\title{
Effect of Meteorological Variables on Air Pollutants Variation in Arid Climates
}

\section{Jamal A Radaideh}

Civil and Environmental Department, King Faisal University, Al Hofuf 31982, Saudi Arabia

\begin{abstract}
Air quality and climatic factors are closely linked through atmospheric chemical reactions and dynamic processes. This work based on a study conducted over an area of industrial plant located in Saudi Arabia during three consecutive weeks with noticeable varying meteorological parameters in the last week of survey with the main objective to examine the role of climatic factors on differences in air pollutant concentration. A systematic analysis of air pollutants including TVOC, $\mathrm{CO}, \mathrm{SO}_{2}, \mathrm{NO}_{2}$, and $\mathrm{O}_{3}$ and meteorological parameters including temperature, wind speed (WS), and relative humanity $(\mathrm{RH})$ was conducted for a continuous period of 3 weeks from March to mid-April 2015. Acquired results indicate most of observed key air pollutants increase with increase in relative humidity, except $\mathrm{NO}_{2}$, which experiences a decrease in concentrations simultaneous with increasing relative humidity. This survey study suggests that concentrations of TVOC concentrations increase by $201 \%$, CO by $15.2 \%, \mathrm{SO}_{2}$ by $21.6 \%$ and ozone by $16 \%$ as a direct contribution to relative humidity change. While $\mathrm{NO}_{2}$ experiences a decrease by $53.4 \%$ as a result of increase in relative humidity. Ozone exhibits only slightly spatial variation due to sudden change of meteorological variables.
\end{abstract}

Keywords: Industrial key air pollutants; Meteorological components; Correlation

Abbreviations: CO: Carbon Monoxide; $\mathrm{CO}_{2}$ : Carbon Dioxide; GHG: Green House Gas; NAAQS: National Ambient Air Quality Standard; NO: Nitric Oxide; $\mathrm{NO}_{2}$ : Nitrogen Dioxide; NOx: Oxides of Nitrogen; $\mathrm{O}_{3}$ : Ozone; PAN: Peroxyacetyl Nitrate (PAN); ppb: parts per billion; ppm: parts per million; $\mathrm{PM}_{10}:$ Particulate Matter with aerodynamic diameter 10 micrones or less; $\mathrm{PM}_{25}$ : Particulate Matter with aerodynamic diameter 2.5 micron or less; R: Correlation and regression coefficient RH: Relative Humidity; $\mathrm{SO}_{2}$ : Sulfur Dioxide; TVOC: Total Volatile Organic Compounds; TSP: Total Suspended Particles; VOC: Volatile Organic Compounds; TVOC: Total Volatile Organic Compounds.

\section{Introduction}

Air pollutants as identified and regulated through environmental legislations in all parts of the world (NAAQS of EPA, EU-directives and WHO AQG) [1,2], varying in their origin, chemical compositions, reaction kinetics, persistence in the environment, ability for dispersion and movement over long or short distances and their possible effects on health of human, plants and animals. However, these pollutants share some similar properties and they can be divided into four categories [3]; gaseous pollutants and vapors $\left(\mathrm{SO}_{2}, \mathrm{NOx}, \mathrm{CO}\right.$, ozone, Volatile Organic Compounds), persistent organic pollutants (dioxins), heavy metals (lead, mercury) and fine particulate Matter $\left(\mathrm{PM}_{2.5}, \mathrm{PM}_{10}\right.$ and TSP). In addition Clean Air Act of 1970 and its announced amendments in 1977 through 1990, classified air pollutants into two types according to the nature of formation: primary pollutants which are emitted from their sources directly to the atmosphere through industry, traffic and domestic activities, and secondary pollutants which result from the chemical reactions between the primary pollutants, such as smog, ozone and PAN [4].

A very wide range of industries and industrial processes produce emissions of air pollutants, both the classical pollutants but also more unfamiliar pollutants that may be specific to a particular industrial process and may arise from leakage of an intermediate or product from a chemical plant. At the present time, vehicular pollution is the main source of anthropogenic air pollution that degrades the quality of air in the cities of industrialized countries, whereas industrial pollution still presents the largest source of air pollution in countries undergoing industrialization. However, other sources of pollution, such as desert sand storms, sea salt, wildfires, and volcanic ash are considered as natural pollution and have to be added to levels of particulates that pollute the ambient atmosphere [5,6]. Air quality and meteorological factors are closely linked through atmospheric chemical reactions and dynamic processes.

Increased air pollutant concentrations in the urban environment do not typically result from sudden increases in emissions, but rather from meteorological conditions that impede dispersion in the atmosphere or result in increased pollutant generation $[7,8]$. There are many aspects of variations in air pollution that are still difficult to understand. One of these aspects is the estimation of the sensitivity of air pollutants to individual meteorological parameters. A combination of meteorological variables important to these conditions includes temperature, winds, radiation, atmospheric moisture, and mixing depth [7]. It is well known that concentrations of pollutant within local air sheds are affected by meteorological parameters [7-11].

Meteorological conditions play a crucial role in ambient air pollution by affecting both directly and indirectly the emissions, transport, formation, and deposition of air pollutants. Several research studies pertaining to weather and atmospheric pollution effects on humans have established associations between meteorological conditions and parameters to air pollutants. These studies have provided evidence that meteorological factors such as wind velocity and direction, temperature and relative humidity can significantly affect air quality [9,11-13].

The most important role of meteorology is in the dispersion, transformation and removal of air pollutants from atmosphere [14]. Also, in a study [15] has suggested that adverse health consequences of ambient ozone pollution increase when temperatures are higher.

*Corresponding author: Jamal A Radaideh, Civil and Environmental Department King Faisal University, Al Hofuf 31982, Saudi Arabia, Tel: 00962135895442; E-mail: jalradaideh@kfu.edu.sa

Received November 25, 2017; Accepted May 31, 2017; Published June 19, 2017

Citation: Radaideh JA (2017) Effect of Meteorological Variables on Air Pollutants Variation in Arid Climates. J Environ Anal Toxicol 7: 478. doi: 10.4172/21610525.1000478

Copyright: () 2017 Radaideh JA, This is an open-access article distributed under the terms of the Creative Commons Attribution License, which permits unrestricted use, distribution, and reproduction in any medium, provided the original author and source are credited. 
Citation: Radaideh JA (2017) Effect of Meteorological Variables on Air Pollutants Variation in Arid Climates. J Environ Anal Toxicol 7: 478. doi: 10.4172/2161-0525.1000478

Page 2 of 12

Aerosol sulfate concentrations are influenced by temperature-dependent oxidation of $\mathrm{SO}_{2}$ in both the gas and aqueous phases Seinfeld et al. [16] also found that the concentrations of oxidants that react with $\mathrm{SO}_{2}$ to be dependent on temperature and sunlight intensity. Levels of semi-volatile nitrate and organic aerosol species are temperature and relative humidity dependent [17]. A further study [18] revealed that fine particles are controlled mainly by wind and temperature and $60 \%$ to $74 \%$ day-today variation of particulate matter concentrations can be reasoned by meteorological parameters and that any change of the concentration of $\mathrm{PM}_{2.5}$ is well related to pressure, relative humidity, and wind speed.

The influence of weather on Ozone emission has been examined many times. All studies came out with the observation that the formation of Ozone is strongly depend on climatological conditions. Results of ozone investigations [19] indicate that varying temperature and mixing height most strongly affect ozone conditions, while relative humidity is the strongest predictors of PM concentrations. Meteorological variability typically accounts for $40-70 \%$ of ozone variability and $20-50 \%$ of PM variability [20]. The strong linkage between weather conditions and pollutant levels can obscure the effects of changing emission levels over time. Much of the inter annual variation in ozone can be attributed to variations in meteorological conditions that control ozone accumulation $[15,21]$. Most important meteorological variables for predicting ozone were daily maximum surface temperature, wind speed average relative humidity, opaque cloud cover, and morning mixing height.

In fact, limited studies are performed to determine the interactions between meteorological factors and air pollutants in an arid environment. Developing country especially those having a desert arid climate, characterized by extreme heat during sunshine and an abrupt drop in temperature at night and a very low rainfall and extremely high evapotranspiration rates suffer at most from air pollution. Because of the influence of a subtropical high-pressure system and the many fluctuations in elevation, there is considerable variation in temperature and humidity [22]. These countries (Middle East and North Africa region) experience very often dust storms which have been shown to have severe impacts on human and animal health. When visibility reaches near-zero serious traffic accidents have cost lives and cause traffic collapsing when high ways cut out of service for extended periods of time [23]. Beside fine particles, spores and contaminants associated with dust and aerosol can adversely impact human health, causing a range of issues from respiratory infections to toxic exposure [24,25]. Understanding the complex issue of air pollutants and quantifying the contribution of different meteorological parameters, in parallel with the given widespread concern of ambient air pollution in developing countries and its broad ranging impacts, the present study is focused on investigation of air pollution occurring at one of the densest industrial areas located in Saudi Arabia. In this paper the interaction between air pollutant levels and meteorological parameters is analyzed over an area at industrial plant located in Saudi Arabia, where published materials on air quality and climate related issue is very limited to a few active and passive sites in the region. This study will help better understand the interaction between meteorological conditions and various air pollutants, which is required for developing effective regional air quality management plan.

The main objective of this study is to present the spatial distributions of selected gaseous pollutants $\left(\mathrm{SO}_{2}, \mathrm{NO}_{2}, \mathrm{CO}, \mathrm{CO}_{2}\right.$, TVOC and Ozone) and particulate matter $\left(\mathrm{PM}_{2.5}, \mathrm{PM}_{10}\right)$ within the study area and to estimate the degree of air pollution likely to arise in close relationship to change in ambient meteorological parameters.

\section{Materials and Methods}

Data are collected during a survey study conducted in an industrial area located in eastern part of Saudi Arabia, one of the densest industrial areas in the region. The study extends over 4 continuous weeks from mid -March to mid-April 2015. The last week experiences a dramatic change in weather components (temperature and relative humidity).

Air sampling using air quality monitoring mobile station was used to perform essential measurements of potential air pollutants during the study period. The survey study was conducted during 4 consecutive weeks with noticeable drop in ambient outside temperature and varying relative humidity in the last week. The drop in ambient temperature and an increase in relative humidity in the last week enables conclusions about logical relationships between air pollutants levels and meteorological parameters. A total of 200 measurement samples are collected over the course of study at selected points $\left(\mathrm{L}_{1}-\mathrm{L}_{20}\right)$ outside factories and workshops as shown in Figures 1-3. Concentrations of particulate matter $\left(\mathrm{PM}_{2.5}\right.$, $\mathrm{PM}_{10}$ and PM1 and TSP) and gaseous air pollutants such as nitrogen dioxides $\left(\mathrm{NO}_{2}\right)$, ozone $\left(\mathrm{O}_{3}\right)$, carbon monoxide $(\mathrm{CO})$, sulfur dioxide $\left(\mathrm{SO}_{2}\right)$, carbon dioxide $\left(\mathrm{CO}_{2}\right)$ and total organic compounds (TVOC) are monitored. Data about Meteorological parameters like temperatures, relative humidity and wind are also simultaneously collected during this survey. In addition to air monitoring mobile station, levels of gaseous pollutants are monitored using Wolf Pack AAQ Instrument. The PM levels are obtained using a particulate matter monitor (AEROCET 531S). The samplers draw air through a filter paper at a known constant rate for 24 hours. The resulting increase in the weight of the filter paper is expressed as the particulate concentration.

\section{Study area}

The study area is located outside the urban boundaries of the nearest city. The area with the coordinates, Latitude: $26^{\circ} 15^{\prime} 31^{\prime \prime} \mathrm{N}$ Longitude: $49^{\circ} 58^{\prime} 5^{\prime \prime} \mathrm{E}$ has a length of 15.57 kilometers and houses about 340 different factories.

The industrial plant was established in 1978 in order to achieve industrial development. The plant houses famous global factories, such as modern industrial companies (Tide), factories for cleaning products (CLOROX), the wooden group factories and many others. The plant is situated in the eastern province of Saudi Arabia. The climate at the measurement site during March-April is the representative for summer season, very hot due to intense solar radiation. The daytime temperature reaches about $40^{\circ} \mathrm{C}$ and nighttime above $30^{\circ} \mathrm{C}$.

\section{Collection of ambient air quality data}

The sampling station is installed at all points assigned for data collection $\left(\mathrm{L}_{1}-\mathrm{L}_{20}\right)$. Each point is supposed to represent a specific area from the whole area of study. Factories are distributed randomly and equally over the area in a way that any measured concentration of an air pollutant couldn't be referred to any specific industry. The sampling station and other instruments used to collect samples was installed at all locations $\left(\mathrm{L}_{1}-\mathrm{L}_{20}\right)$ assigned for data collection. Each selected point is supposed to represent a specific area from the whole area of study. Factories are distributed randomly and equally over the area in a way that any measured concentration of any air pollutant couldn't be referred to a specific industry. Critical air pollutants $\mathrm{SO}_{2}, \mathrm{NO}_{2}, \mathrm{CO}, \mathrm{O}_{3}$, TVOC together with meteorological parameters (relative humidity and temperature) were monitored.

The collection of samples is conducted in 3 consecutive weeks. In total 200 individual measurement results were obtained during 50 
Citation: Radaideh JA (2017) Effect of Meteorological Variables on Air Pollutants Variation in Arid Climates. J Environ Anal Toxicol 7: 478. doi: $10.4172 / 2161-0525.1000478$

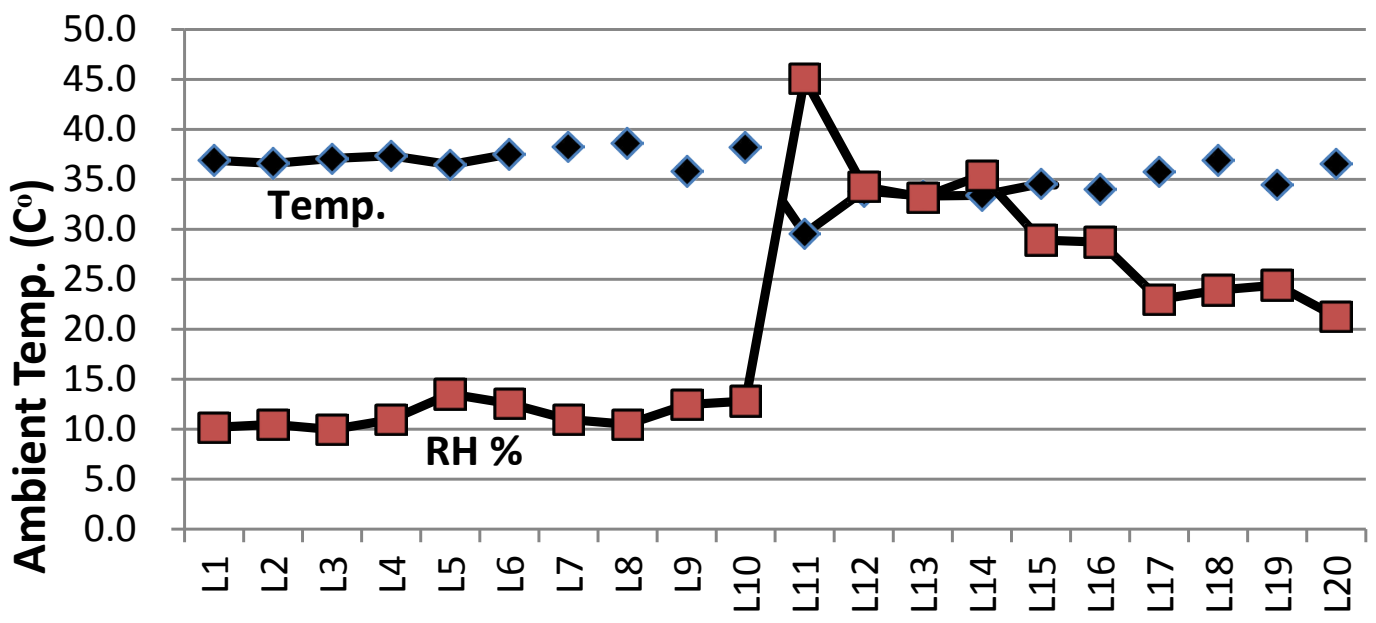

Relative Humidity \%

Figure 1: Observed change of meteorological conditions (Temp. and RH) monitored during sampling periods.

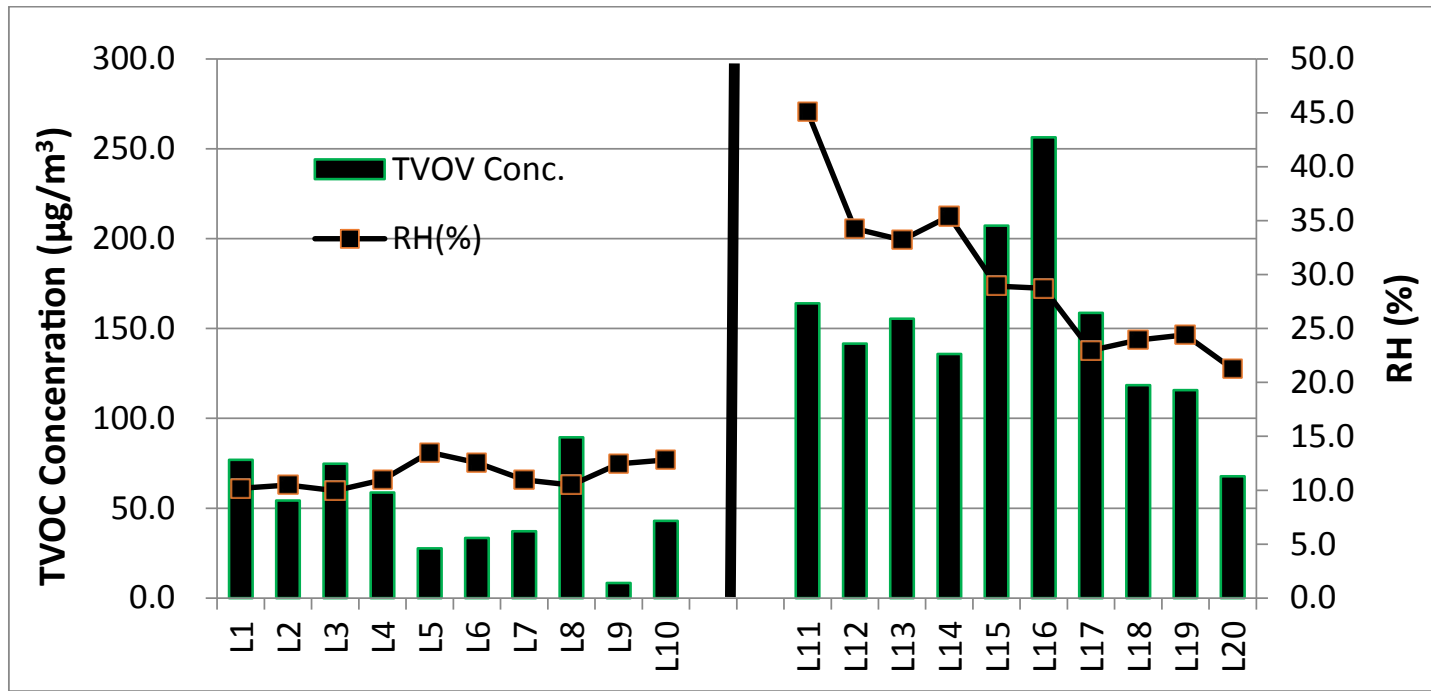

Figure 2: Observed concentrations of TVOC at study area in relation to meteorological variables.

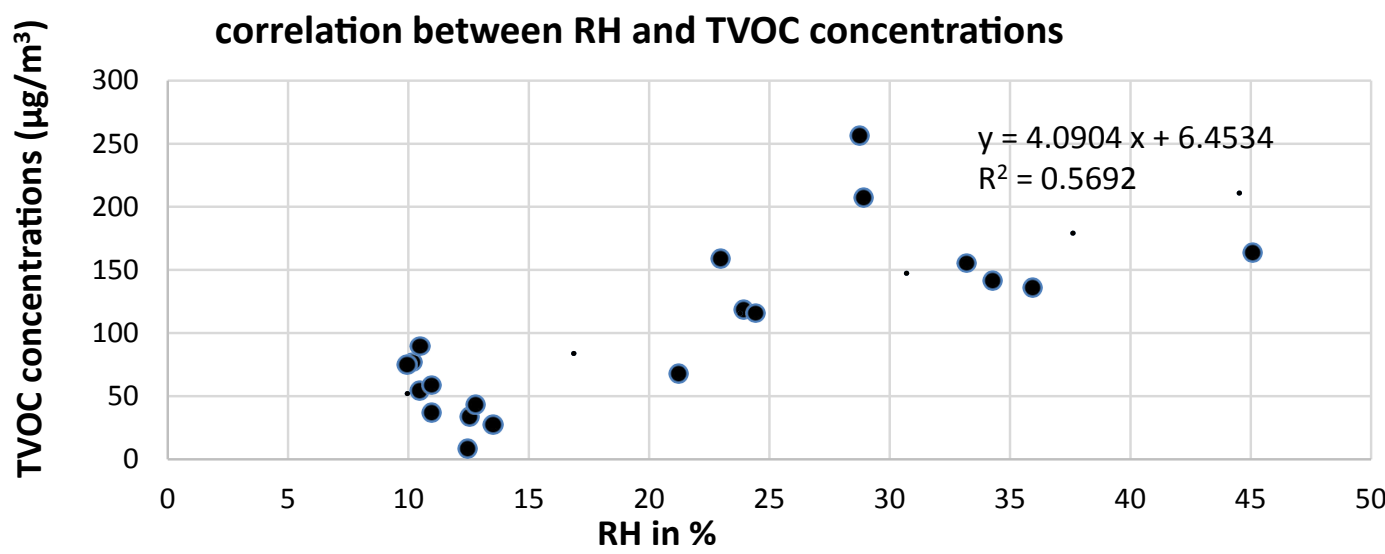

Figure 3: Correlation curve of TVOC concentrations monitored at locations L1-L20 with the RH. 
Citation: Radaideh JA (2017) Effect of Meteorological Variables on Air Pollutants Variation in Arid Climates. J Environ Anal Toxicol 7: 478. doi: $10.4172 / 2161-0525.1000478$

Page 4 of 12

different measurement campaigns. A major variation in meteorological conditions, in particular relative humidity increased strongly and to a lesser extent the temperature, thus making these two weeks appropriate time to collect samples and to evaluate the influence of climate parameters on the results. Figure 1 and Table 1 demonstrate the observed variation in meteorological conditions in both sampling weeks. Wind speed was during both sampling periods negligible small.

\section{Data analysis}

As soon as the measuring devices are calibrated and turned on, recording of pollution levels at each assigned location has started. The recorded data pass through rectify units and an average value is displayed. For each potential pollutant about 40-50 values are recorded during the operation period for one measurement of 2-3 minutes. The hourly mean concentrations of the measured pollutants during the two periods of study are registered and tabulated. In addition meteorological parameters such as temperature and relative humidity are recorded continuously and simultaneously. The average values of all readings (40-50 readings) for each considered potential pollutant is presented in Table 2.

\section{Analysis of results}

The purpose of statistical analysis of monitored air pollution components was to determine the extent of existing linear relationship(s), or lack thereof, between meteorological parameters and pollutant concentrations. One approach that has proven effective in measuring the effects of meteorological factors on air pollution is statistical modeling [26]. Statistical models are well suited for quantifying and visualizing the nature of pollutant response to individual meteorological parameters as they directly fit to the patterns that arise from the observed data [27].

Analysis of observed (TVOC) concentrations: Volatile organic compounds (VOC) comprise a very wide range of substances such as hydrocarbons, oxygenates, halogenates and other carbon compounds existing in the atmosphere in the vapor phase [28]. The predominant source is typically through leakage from pressurized systems (natural gas, methane) combustion of fossil or evaporation of a liquid fuel such as benzene from the fuel tank of a vehicle [29]. VOCs play a significant role in the formation of ozone and fine particulates in the atmosphere. Under sunlight [30], VOCs react with nitrogen oxides emitted mainly from vehicles, power plants and industrial activities to form ozone, which in turn helps the formation of fine particulates. Photochemical reactions of volatile organic compounds (VOCs) and nitrogen oxides (NOx) under high temperatures lead to ozone formation [16,31]. The accumulation of ozone, fine particulates and other gaseous pollutants results in smog that reduces visibility. In general, volatile organic compounds (VOCs) are organic compounds having a tendency due to chemical composition, to evaporate easily at room temperature and atmospheric pressure. Since the volatility of a compound is generally higher the lower its boiling point temperature, therefore, the volatility of organic compounds is sometimes defined and classified according their boiling points. According to (EU-Directive 2004/42/CE) [32] a VOC is any organic compound having an initial boiling point less than or equal to $250^{\circ} \mathrm{C}\left(482^{\circ} \mathrm{F}\right)$ measured at a standard atmospheric pressure of $101.3 \mathrm{kPa}$ ( $1 \mathrm{~atm}$. at sea level).

Figure 2 and Table 2 illustrate data of monitored TVOC concentrations at the study area, both show that the concentrations of TVOC are in the range of $27.73-89.51 \mu \mathrm{g} / \mathrm{m}^{3}$ with an average of 53.39 $\mu \mathrm{g} / \mathrm{m}^{3}$ for measurements conducted at locations $\mathrm{L}_{1}-\mathrm{L}_{10}$, while during the second measurement period concentrations values are ranging from $115.73-256.40 \mu \mathrm{g} / \mathrm{m}^{3}$ making an average of $152.123 \mu \mathrm{g} / \mathrm{m}^{3}$ found at locations $\mathrm{L}_{11}-\mathrm{L}_{20}$, which means a $201 \%$ increase in mean value.

This observed significant increase in TVOC levels (aver. $\mathrm{L}_{11}-\mathrm{L}_{20}$ / aver $\mathrm{L}_{1}-\mathrm{L}_{10}=3.3$ ) is attributed to change in meteorological components between both sampling periods. The sudden increase in concentrations of TVOC at sampling sites $\left(\mathrm{L}_{11}-\mathrm{L}_{20}\right)$ is attributed to slightly decrease in temperatures and the strong climb in relative humidity as illustrated in Table 1 . The ambient air temperatures during the first period ranged from $35.81^{\circ} \mathrm{C}$ to $38.60^{\circ} \mathrm{C}$ and the relative humidity values were in the range of $9.95 \%-15.93 \%$, in average $11.08 \%$. Comparatively, during the second period the temperatures were observed in range of $29.56^{\circ} \mathrm{C}$ to $36.90{ }^{\circ} \mathrm{C}$, whilst, the relative humidity values were in the range of $21.24 \%-45.08 \%$ resulting an average of $29.82 \%$, which means a $170 \%$ increase.

Influence of temperature on VOC concentrations: Although temperatures decrease slightly between first and second sampling

\begin{tabular}{|c|c|c|c|c|c|c|c|}
\hline \multirow{2}{*}{ Sampling periods } & \multicolumn{4}{|c|}{ Ambient Temperatures ${ }^{\circ} \mathrm{C}$} & \multicolumn{3}{|c|}{ Relative humidity \% } \\
\hline & Aver. & Min. & Max. & SD & Aver. & Min. & Max. \\
\hline $1^{\text {st }}$ period at $\mathrm{L}_{1}-\mathrm{L}_{10}$ & 37.29 & 35.814 & 38.605 & 1.272 & 11.08 & 9.95 & 12.81 \\
\hline $2^{\text {nd }}$ period at $L_{11}-L_{20}$ & 34.24 & 29.56 & 36.91 & 7.317 & 29.82 & 21.25 & 45.03 \\
\hline Increase/decrease & $8.2 \%$ & & & & $170 \%$ & & \\
\hline
\end{tabular}

Table 1: Meteorological conditions (Temp. and $\mathrm{RH}$ ) as monitored during sampling periods.

\begin{tabular}{|c|c|c|c|c|c|c|c|c|}
\hline \multirow{2}{*}{ Pollutant } & \multicolumn{4}{|c|}{$1^{\text {st }}$ Sampling period at $L_{1}-L_{10}$} & \multicolumn{4}{|c|}{$2^{\text {nd }}$ Sampling period at $L_{11}-L_{20}$} \\
\hline & Aver. & Min. & Max & SD & Aver. & Min. & Max & SD \\
\hline TVOC $\left(\mu \mathrm{g} / \mathrm{m}^{3}\right)$ & 50.402 & 8.34 & 89.51 & 25.19 & 150.123 & 67.78 & 256.4 & 25.19 \\
\hline
\end{tabular}

Table 2: Statistical analysis of monitored TVOC concentration at locations $L_{1}-L_{10}$ and at locations $L_{11}-L_{20}$ of the study area.

\begin{tabular}{|c|c|c|c|c|c|c|c|c|}
\hline \multirow{2}{*}{ Pollutant } & \multicolumn{4}{|c|}{$1^{\text {st }}$ Sampling period at $L_{1}-L_{10}$} & \multicolumn{4}{|c|}{$2^{\text {nd }}$ Sampling period at $L_{11}-L_{20}$} \\
\hline & Aver. & Min. & Max & SD & Aver. & Min. & Max & SD \\
\hline CO (ppm) & 1.32 & 1.23 & 1.43 & 0.071 & 1.52 & 1.80 & 1.18 & 0.171 \\
\hline
\end{tabular}

Table 3: Statistical analysis of monitored $C O$ concentration at locations $L_{1}-L_{10}$ and at locations $L_{11}-L_{20}$ of the study area. 
periods, results of analysis revealed that TVOC concentrations correlated negatively strong with ambient temperatures $\left(R^{2}=-0.4289\right)$. A mathematical model developed by [33] predicts that the chamber formaldehyde concentration increases with increasing temperature. Rubin et al. [34] estimated that at least $1.3 \pm 0.4 \%$ increase in daily total (exhaust+evaporative) VOC emissions from motor vehicles per $1{ }^{\circ} \mathrm{C}$ increase in maximum temperature. Tailpipe emissions from vehicles are only weakly temperature dependent, for example due to the increase in fuel consumption for air conditioning on hot days [35].

Influence of relative humidity on VOC concentrations: The correlation curve as shown in Figure 3 confirms the strong positive correlation of TVOC concentrations with the prevailing relative humidity RH. A correlation coefficient of $\mathrm{R}^{2}=0.5692$ describes the relationship. It means that TVOC concentrations in ambient air are intensified with increasing relative humidity. A study confirms that temperature is one of the environmental parameters that influences VOC emissions from building materials together with air velocity and humidity [36]. Also Bremer et al. and Cox et al. [37,38] reported on emission variations with changes in temperature and concluded that the emitted substances were temperature dependent.

Analysis of carbon monoxide (CO) concentrations: $\mathrm{CO}$ is an important trace gas in the earth's atmosphere, which plays several important roles in the troposphere. $\mathrm{CO}$ is generated from a variety of sources, both natural and anthropogenic. Natural sources include oxidation of methane and natural hydrocarbons, ocean emissions, and emissions from vegetation. In urban areas, however anthropogenic sources including fossil fuel combustion, industrial activities, motor vehicles, biomass burning, and oxidation of anthropogenic hydrocarbons, all contribute for more to the concentration of $\mathrm{CO}$ than natural sources do [39]. Carbon Monoxide (CO) resulted mainly from incomplete combustion of hydrocarbons (HC). Transportation accounts for 70 to $90 \%$ of total CO production $[40,41]$.

In this study, as shown in Figure 4 and Table 3, for all sampling locations $\mathrm{L}_{1}-\mathrm{L}_{10}$, the hourly carbon monoxide concentrations are found to be in the range from 1.23 to $1.43 \mathrm{ppm}$ during the first measurement batch making an average of $1.32 \mathrm{ppm}$, while readings during the second batch were in the range of 1.18-1.8 ppm with an hourly average of 1.41 ppm.

Influence of temperatures and relative humidity on $\mathrm{CO}$ concentrations: Comparing results of first measurement with values of second period, it is to confirm that recorded $\mathrm{CO}$ concentrations correlates very slightly (aver. $\mathrm{L}_{11}-\mathrm{L}_{20} /$ aver $\mathrm{L}_{1}-\mathrm{L}_{10}=1.15$ ) with changing ambient climate factors (temperatures and $\mathrm{RH}$ ). The correlation coefficient $\mathrm{R}^{2}=0.1747$ as shown in Figure 5 describes the weak positive relationship between $\mathrm{CO}$ concentrations and ambient $\mathrm{RH}$. For correlation of $\mathrm{CO}$ concentration with temperatures a correlation coefficient of $\mathrm{R}^{2}=0.0962$.

In a similar study [14] a statistical model is developed to predict the relationship between daily $\mathrm{CO}$ (carbon monoxide) concentration with the pollutant concentration of previous day and climatic factors (wind speed, temperature, relative humidity) and suggested that level of $\mathrm{CO}$ decreases with increasing temperature, but $\mathrm{CO}$ increases with increasing relative humidity and $\mathrm{CO}$ concentration of previous days.

Analysis of observed ozone concentrations: Ground ozone $\left(\mathrm{O}_{3}\right)$ is not a primary air pollutant and is not emitted directly into the air in its chemical form; instead it forms in the atmosphere as a result of a series of complex chemical reactions between oxides of nitrogen (NOx) and hydrocarbons in the presence of sunlight, which together are precursors of ozone. Since source apportionment of $\mathrm{O}_{3}$ is difficult as it is a secondary pollutant, and is not directly emitted from any source, it is imperative to accurately find the sources contributing to $\mathrm{O}_{3}$ concentrations in urban areas in order to take corrective policy measures and develop cleaner technologies. The formation and increase in ozone concentrations occur over a period of a few hours, shortly after sunrise, NO and VOCs react in sunlight to form ozone. Throughout the morning, ozone concentrations increase while NO and VOCs are depleted [15].

Understanding the nature of when and where ozone precursors originate may help understanding day-to-day emissions changes. Ozone concentrations at the ground level depend on the formation and dispersion processes. Formation process mainly depends on the precursor sources, whereas, the dispersion of ozone depends on meteorological factors. In addition, the level of ozone concentration at the surface can be estimated by the result of source and sink mechanism, which predominately rely on the meteorological conditions of the environment.

The results of ozone monitoring at the study area are presented in Figure 6 and Table 4. Average ozone concentrations were found to be in range of 0.068 to $0.088 \mathrm{ppm}$ for samples taken at locations $\mathrm{L}_{1}-$ $\mathrm{L}_{10}$ during the first sampling period. The average for these readings is 0.081 ( $\mathrm{ppm})$. Concentrations monitored during the second period are

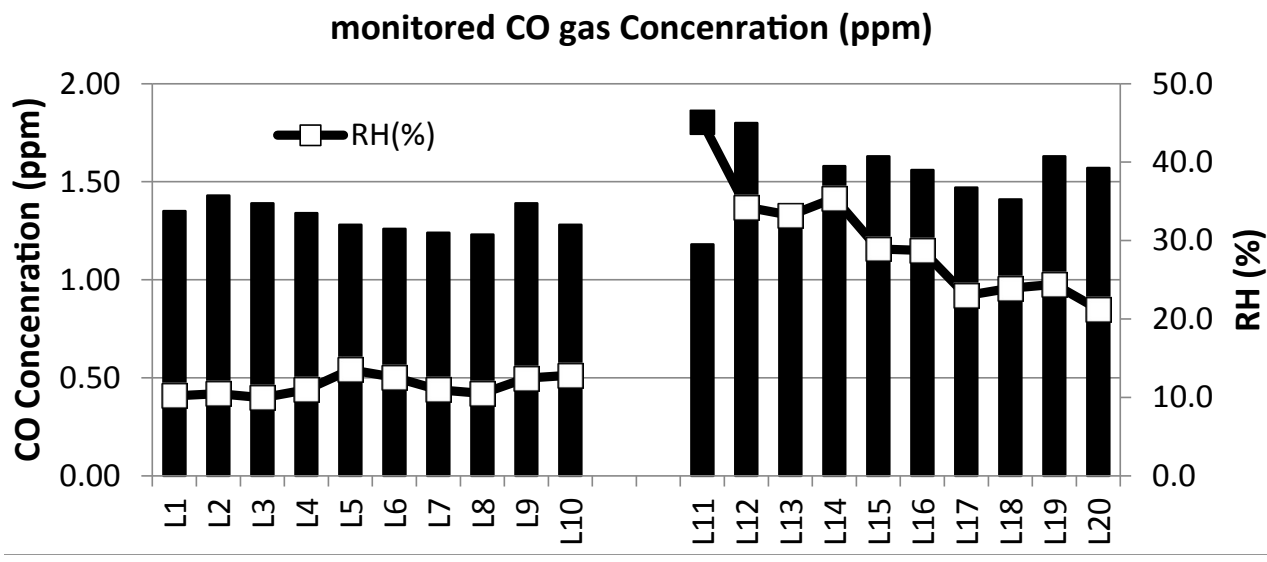

Figure 4: Observed concentrations of carbon monoxide $\mathrm{CO}$ at study area in relation to meteorological variables. 


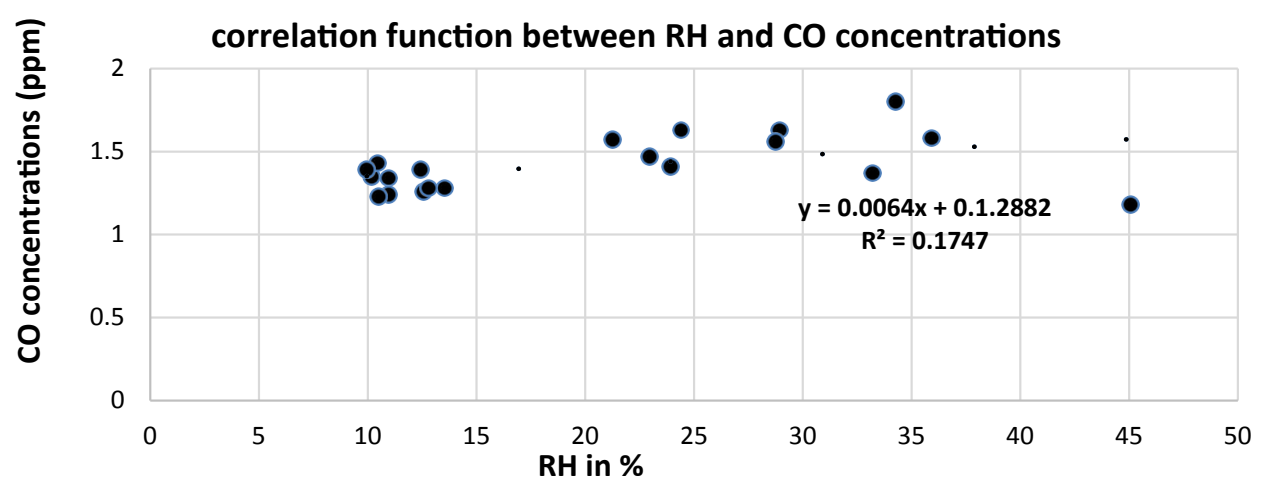

Figure 5: Correlation curve of $\mathrm{CO}$ concentrations with ambient $\mathrm{RH}$.

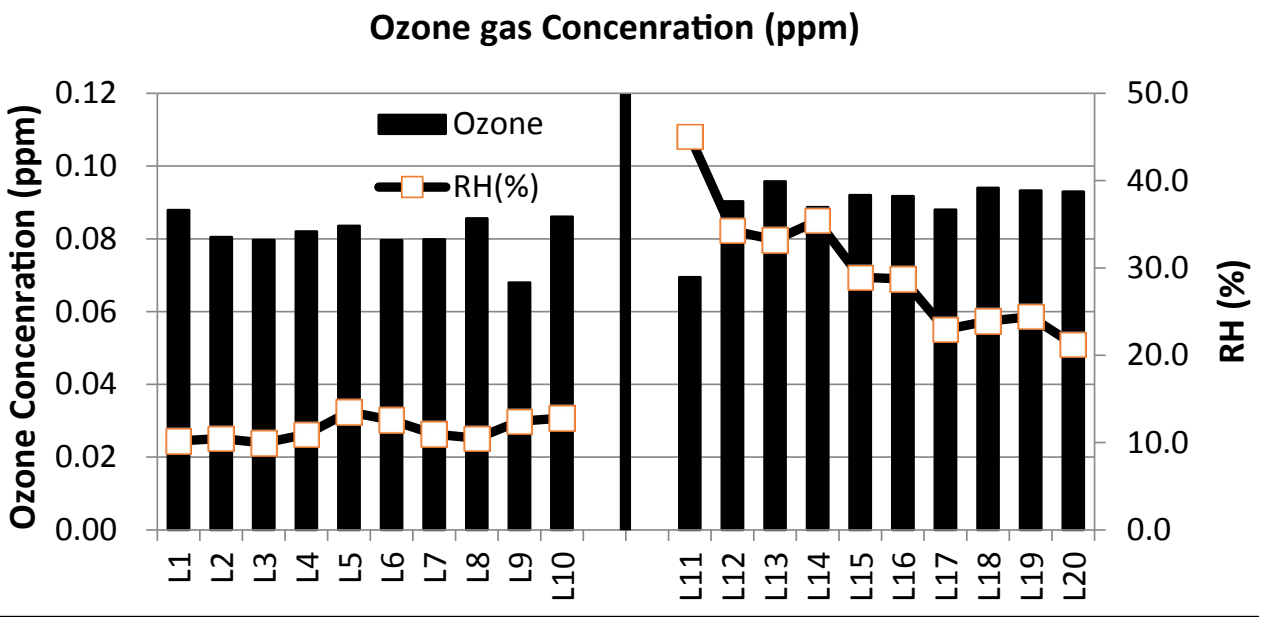

Figure 6: Observed ozone levels at study area in relation to meteorological variables.

\begin{tabular}{|c|c|c|c|c|c|c|c|}
\hline \multirow{2}{*}{ Pollutant } & \multicolumn{3}{|c|}{$1^{\text {st }}$ Sampling period at $L_{\mathbf{1}}-L_{10}$} & \multicolumn{4}{|c|}{$2^{\text {nd }}$ Sampling period at $L_{11}-L_{20}$} \\
\cline { 2 - 6 } & Aver. & Min. & Max & SD & Aver. & Min. \\
\hline Ozone $(p p m)$ & 0.0815 & 0.088 & 0.068 & 0.006 & 0.094 & 0.104 \\
\hline
\end{tabular}

Table 4: Statistical analysis of monitored Ozone concentration at locations $L_{1}-L_{10}$ and at locations $L_{11}-L_{20}$ of the study area.

ranging from 0.069 to $0.096 \mathrm{ppm}$, with an average of 0.094 (ppm). The ozone concentrations vary slightly among sampling locations and with varying meteorological variables during both sampling periods.

However, the measurements obtained from this study reveals that the daily averaged Ozone concentrations are well higher than WHO guideline value of $0.05 \mathrm{ppm}$. It can be noted that not a single data is below this standard limit. Results of ozone concentration during the first week at locations $\mathrm{L}_{1}-\mathrm{L}_{10}$ showed that at these locations, relatively high to moderate ozone concentrations were monitored.

Influence of temperature and relative humidity on ground ozone concentrations: As presented in Figure 7, the correlation between relative humidity and ozone levels couldn't be clearly demonstrated. However a slight increase in ozone levels at locations $\mathrm{L}_{11}-\mathrm{L}_{20}$ is noticeable and could be referred to the increase in ambient relative humidity during the sampling period. The obtained results confirm a very weak positive correlation between ground ozone concentrations and ambient relative humidity (RH). A correlation coefficient in the range of $\mathrm{R}^{2}=0.0645$ as shown in Figure 8 describes these findings. In addition as presented in Table 4 and Figure 7, the 1-h and the daily distribution of monitored ground ozone exhibit slightly changes indicating little association with ambient temperature. Consequently, this study suggests that ground ozone doesn't correlate or correlates very slightly with changing temperature. A correlation coefficient of $\mathrm{R}^{2}=0.0002$ is calculated (Table 5) to support this hypothesis.

Comparative results found by Sevda Ocak et al. [14] through the use of mathematical model that daily traffic-related pollutant concentrations are not only influenced by daily meteorological parameters but also by the pollutant concentration of previous day. Ozone concentration increased with increasing wind speed, temperature, relative humidity and $\mathrm{O}_{3}$ concentration of previous days. Another study reported that meteorological conditions conducive to high ozone, including stagnation events and clear skies, correlate with increasing temperature [35]. A survey study [42] suggested that the peak concentrations of $\mathrm{O}_{3}$ occurred during May to August due to higher temperature and solar radiation which could promote the photochemistry activity. 


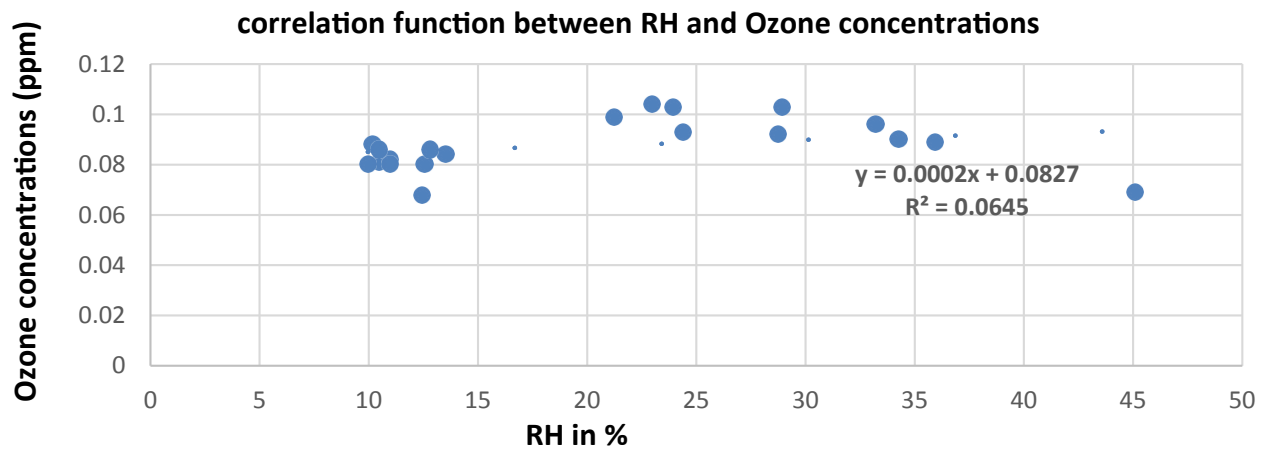

Figure 7: Correlation curve between Ozone and relative humidity $\mathrm{RH}$.

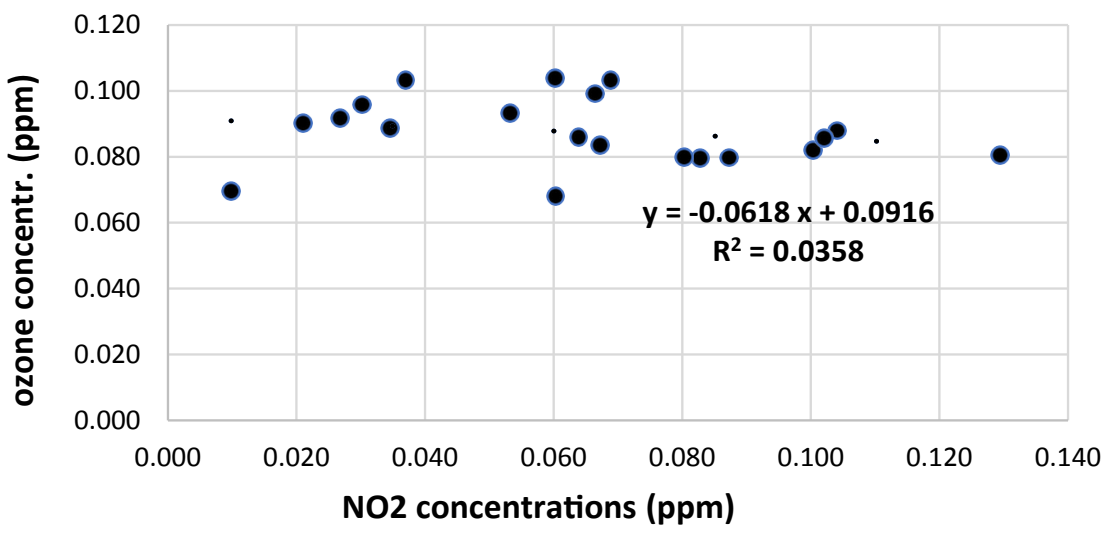

Figure 8: Relationship between monitored $\mathrm{NO}_{2}$ concentrations and ozone concentrations (ppm).

\begin{tabular}{|c|c|c|}
\hline Pollutant & RH $\%$ & Temp. $\mathbf{C}^{\circ}$ \\
\hline TVOC & $\mathrm{R}^{2}=0.5692$ positive & $\mathrm{R}^{2}=0.4289$ negative \\
\hline $\mathrm{O}_{3}$ & $\mathrm{R}^{2}=0.0642$ & $\mathrm{R}^{2}=0.0002$ \\
\hline $\mathrm{NO}_{2}$ & $\mathrm{R}^{2}=0.7806$ negative & $\mathrm{R}^{2}=0.648$ positive \\
\hline $\mathrm{SO}_{2}$ & $\mathrm{R}^{2}=0.0288$ negative & $\mathrm{R}^{2}=0358$ negative \\
\hline $\mathrm{CO}$ & $\mathrm{R}^{2}=0.1747$ positive & $\mathrm{R}^{2}=0.0962$ positive \\
\hline
\end{tabular}

Table 5: Summary of correlation coefficients between monitored air pollutants ambient meteorological components (relative humidity and temperatures).

Ground-level ozone is a major component of smog. Photochemical reactions of volatile organic compounds (VOCs) and nitrogen oxides $\left(\mathrm{NO}_{\mathrm{x}}\right)$ under high temperatures lead to ozone formation [16,31]. Often, $\mathrm{NO}_{\mathrm{x}}$ alone controls the ozone formation, but increases with increasing VOC [31,43]. The lifetime of the ozone depends on breaking of ozone and dispersions factors and the effects of daily VOC (expressed as nonmethanic hydrocarbons or NMHC) and NOx concentrations on ozone behavior are well known [44].

In present case, ozone concentrations increase, whilst $\mathrm{NO}_{2}$ concentrations decrease. In fact, a very weak negative correlation is found between ozone concentrations and the ambient $\mathrm{NO}_{2}$ concentrations at the study area. As presented in Figure 8, a correlation coefficient of $\mathrm{R}^{2}=0.0358$ is resulted, while a positive correlation could be seen between ozone production and ambient TVOC concentrations with a correlation coefficient of $\mathrm{R}^{2}=0.2725$ (Figure 9).
Analysis of $\mathrm{NO}_{2}$ concentrations: Oxides of nitrogen are one of six principal (or criteria) pollutants for which EPA has established national ambient air quality standards (NAAQS) of USEPA. 2008 Final Report for NOx). The principal sources of nitrogen dioxide are traffic and to a lesser extent industry, shipping and households. High nitrogen dioxide levels, combined with ultrafine particles and other oxidants, have become one of the major air pollution problems in urban areas all over the world. Nitrogen oxides are one of the main components of the mixture of pollutants classically referred to as photochemical smog [45].

Table 6 and Figure 10 show spatial distribution of daily maximum 1-h $\mathrm{NO}_{2}$ concentrations from end March to mid- April 2015. It is apparent from Table 6 that the daily 1-h $\mathrm{NO}_{2}$ concentrations ranged from $0.06 \mathrm{ppm}$ to $0.104 \mathrm{ppm}$ for samples taken at locations $\mathrm{L}_{1}-\mathrm{L}_{10}$ during the first measuring period with a mean of $(0.88 \mathrm{ppm})$. The $\mathrm{NO}_{2}$ concentrations taken during the second period at Locations $\mathrm{L}_{11}-\mathrm{L}_{20}$ are ranging from 0.01 to $0.069 \mathrm{ppm}$ with an average of $(0.41 \mathrm{ppm})$ for this sampling batch. It has been noticed that the results were fluctuating among locations.

In addition, Figure 10 shows clearly the decrease of $\mathrm{NO}_{2}$ levels taken during the $2^{\text {nd }}$ sampling batch $\left(\right.$ at $\left.\mathrm{L}_{11}-\mathrm{L}_{20}\right)$ against those monitored during the first sampling period at locations $\left(\mathrm{L}_{1}-\mathrm{L}_{10}\right)$.

Influence of relative humidity and temperature on $\mathrm{NO}_{2}$ concentrations: Variations in meteorological parameters (temperatures 


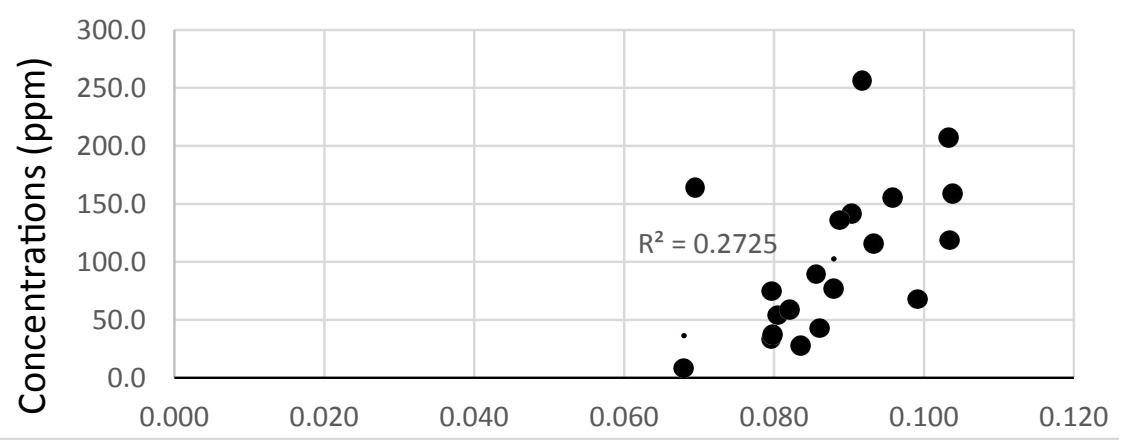

Figure 9: Correlation curve of ozone formation with ambient TVOC at the study area

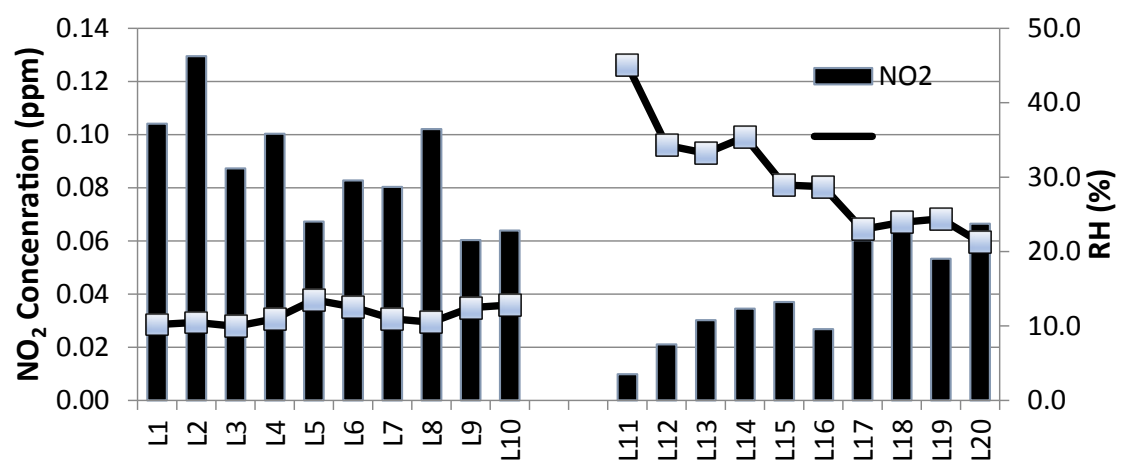

Figure 10: Average values of $\mathrm{NO}_{2}$ concentrations monitored at locations L1-L20 during both sampling periods.

and relative humidity) could be seen as cause for the concentration drop experienced between values at $\mathrm{L}_{1}-\mathrm{L}_{10}$ and those found at $\mathrm{L}_{11}-\mathrm{L}_{20}$. Consequently, it is to conclude that $\mathrm{NO}_{2}$ concentrations decrease as relative humidity increase, but decrease as temperature decrease. The negative correlation presented in Figure 11 indicates that probably high temperatures result in higher dispersion and dilution of air pollutants, thus resulting a decrease in monitored concentrations of $\mathrm{NO}_{2}$. Figure 11 shows the correlation curve between ambient relative humidity and monitored $\mathrm{NO}_{2}$ concentrations. Accordingly, this study confirms that a strong negative correlation exists with a correlation coefficient $\mathrm{R}^{2}=0.7806$. Because temperatures and relative humidity are correlated negatively with each other, $\mathrm{NO}_{2}$ correlated positively with ambient temperatures with a correlation coefficient of $\mathrm{R}^{2}=0.648$. These findings correlate to those reported in related studies $[46,47]$.

Analysis of sulfur dioxide $\mathrm{SO}_{2}$ concentrations: By far Sulfur dioxide $\left(\mathrm{SO}_{2}\right)$ is derived from the combustion of sulfur-containing fossil fuels and is a major air pollutant in many parts of the world $[2,29]$. Fossil fuels, most notably coal and oil, contain varying amounts of sulfur according to their source but typically between $1 \%$ and $5 \%$. On combustion, the sulfur in the fuel is converted almost quantitatively to sulfur dioxide. The primary NAAQS- guideline for SOx, with $\mathrm{SO}_{2}$ serving as the indicator, is set at 0.14 parts per million (ppm), averaged over a $24 \mathrm{~h}$ period, not to be exceeded more than once per year, and $0.030 \mathrm{ppm}$ as annual arithmetic mean.

However, recorded distribution levels of $\mathrm{SO}_{2}$ during first measuring period at locations $\mathrm{L}_{1}-\mathrm{L}_{10}$ maintain higher levels than levels monitored during second measuring period at locations $\mathrm{L}_{11}-\mathrm{L}_{20}$. As Table 7 shows the mean of 1-h levels of $\mathrm{SO}_{2}$ for $1^{\text {st }}$ period at $\mathrm{L}_{1}-\mathrm{L}_{10}$ equals $0.500 \mathrm{ppm}$ and climbs slightly during second sampling period to $0.608 \mathrm{ppm}$.
Influence of relative humidity and temperature on $\mathrm{SO}_{2}$ concentrations: A clear dependency of $\mathrm{SO}_{2}$ concentrations with the relative humidity couldn't be established. However, the small increase in concentrations at locations $\mathrm{L}_{11}-\mathrm{L}_{20}$ compared to levels of $\mathrm{SO}_{2}$ monitored at $\mathrm{L}_{1}-\mathrm{L}_{10}$ could be referred to increase in relative humidity. This clearly demonstrated through the correlation curve of Figures 12 and 13 . The overall correlation of $\mathrm{SO}_{2}$ concentrations with ambient $\mathrm{RH}$ could be seen as positive but weak with a correlation coefficient $\mathrm{R}^{2}=0.0288$. A correlation coefficient of $\mathrm{R}^{2}=-0358$ describes that the association between $\mathrm{SO} 2$ concentrations and ambient temperature is very weak and negative.

\section{Discussion}

The present work was conducted during a three consecutive week's survey study in March-April, 2015, a period tainted by a sudden change in weather conditions (temperature and the rate of relative humidity) during sampling procedure. The analysis of samples examines the differences in key air pollutant concentrations to found out major variations in concentrations due to change in climatic factors. Therefore, obtained results of the study are found appropriate to suggest a relationship between the change in pollution levels and climatic variables, also to derive possible predictions of sequences of climate change in regard to air pollution. By means of available data sets of observations from air monitoring and meteorological stations, calculating statistical relationship among the variables is made possible by using some statistical techniques such as regression analysis. Statistical models, establish how close relationships are between concentration estimates and values actually measured. 


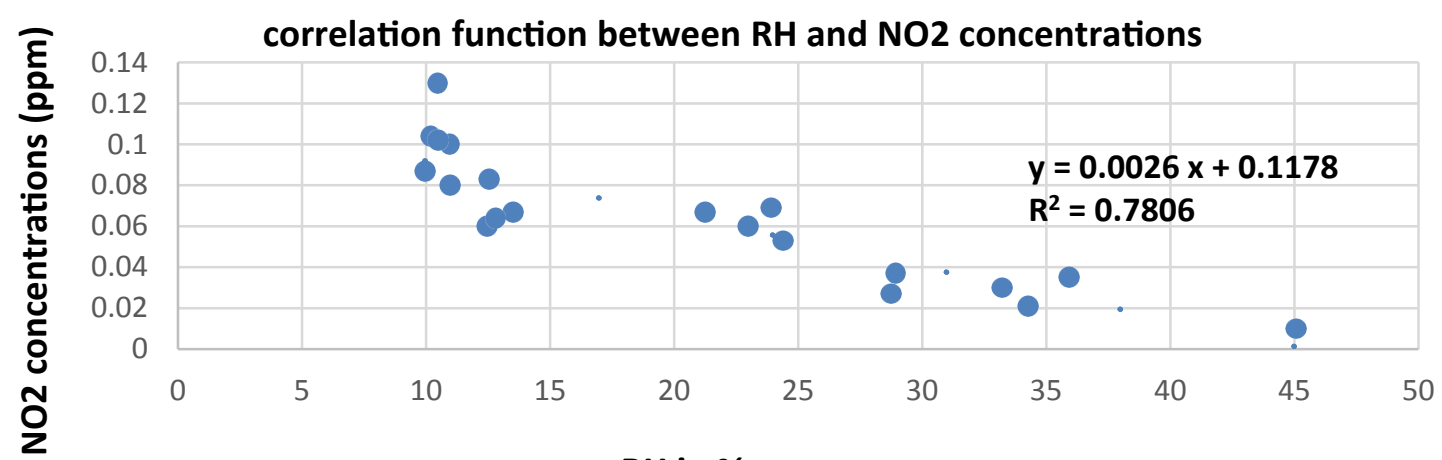

RH in \%

Figure 11: Correlation curve of $\mathrm{NO}_{2}$ concentrations with ambient $\mathrm{RH}$.

\section{$\mathrm{SO}_{2}$ gas Concenration (ppm)}

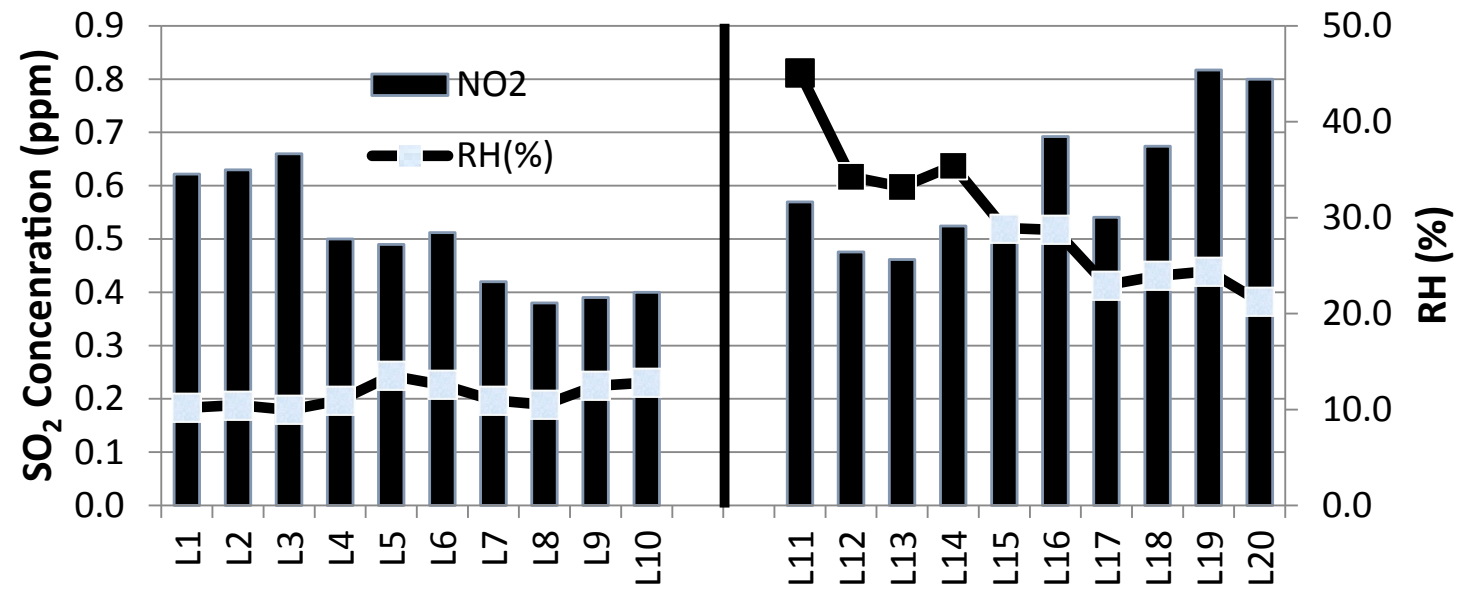

Figure 12: Observed $\mathrm{SO}_{2}$ concentration at study area in relation to meteorological variables.

\begin{tabular}{|l|c|c|c|c|c|c|c|c|}
\hline \multirow{2}{*}{ Pollutant } & \multicolumn{3}{|c|}{$\mathbf{1}^{\text {st }}$ Sampling period at $\mathrm{L}_{\mathbf{1}}-\mathrm{L}_{\mathbf{1 0}}$} & \multicolumn{3}{|c|}{$\mathbf{2}^{\text {nd }}$ Sampling period at $\mathbf{L}_{\mathbf{1 1}}-\mathrm{L}_{\mathbf{2 0}}$} \\
\cline { 2 - 9 } & Aver. & Min. & Max & SD & Aver. & Min. & Max & SD \\
\hline NO $_{\mathbf{2}}$ (ppm) & 0.0877 & 0.060 & 0.130 & 0.022 & 0.041 & 0.010 & 0.069 & 0.02 \\
\hline
\end{tabular}

Table 6: Statistical analysis of monitored $\mathrm{NO}_{2}$ concentration at locations $\mathrm{L}_{1}-\mathrm{L}_{10}$ and at locations $\mathrm{L}_{11}-\mathrm{L}_{20}$ of the study area.

\begin{tabular}{|c|c|c|c|c|c|c|c|c|}
\hline \multirow{2}{*}{ Pollutant } & \multicolumn{3}{|c|}{$1^{\text {st }}$ Sampling period at $\mathrm{L}_{1}-\mathrm{L}_{10}$} & \multicolumn{4}{|c|}{$\mathbf{2}^{\text {nd }}$ Sampling period at $\mathrm{L}_{11}-\mathrm{L}_{20}$} \\
\cline { 2 - 9 } & Aver. & Min. & Max & SD & Aver. & Min. & Max & SD \\
\hline SO $_{2}(\mathbf{p p m})$ & 0.500 & 0.380 & 0.660 & 0.106 & 0.608 & 0.461 & 0.817 & 0.129 \\
\hline
\end{tabular}

Table 7: Statistical analysis of monitored $\mathrm{SO}_{2}$ concentration at locations $\mathrm{L}_{1}-\mathrm{L}_{10}$ and at locations $L_{11}-L_{20}$ of the study area.

The relationship between monitored ambient air quality data at study area and meteorological factors, such as wind speed, temperature and relative humidity was investigated. According to the results obtained by the linear and stepwise regression analysis, results exhibit close association between air pollutants and climatic factors, especially relative humidity and ambient temperatures. To better understand the relation between different air pollutants, the correlation coefficients were calculated for each pollutant with temperatures and relative humidity and illustrated in Table 5 . These results confirm the important role of meteorological parameters in air pollution formation and variation on daily basis.

\section{TVOC concentrations}

Statistical data analysis of monitored TVOC levels show a significant increase of TVOC concentrations of $201 \%$ when comparing measurements conducted at locations $\mathrm{L}_{1}-\mathrm{L}_{10}$ and at locations $\mathrm{L}_{11}-\mathrm{L}_{20}$. This observed significant increase in TVOC levels (aver. $\mathrm{L}_{11}-\mathrm{L}_{20} /$ aver $\left.\mathrm{L}_{1}-\mathrm{L}_{10}=3.3\right)$ is attributed to change in meteorological components occurred during both sampling periods. The sudden increase at sampling sites $\left(\mathrm{L}_{11}-\mathrm{L}_{20}\right)$ is mainly attributed to the simultaneous strong climb in relative humidity as illustrated in Table 1. Although there was a slight change in ambient air temperatures, the significant increase of relative humidity (170\%) is the major contributor for TVOC levels variation. Table 5 illustrates statically and clearly the association between TVOC levels and climatic conditions. Concentrations of TVOC as monitored correlate strongly positive with increasing relative humidity $\left(\mathrm{R}^{2}=0.5692\right)$ and moderate negative with decreasing ambient temperatures $\left(\mathrm{R}^{2}=-0.4289\right)$.

A similar study by which a mathematical model is developed 


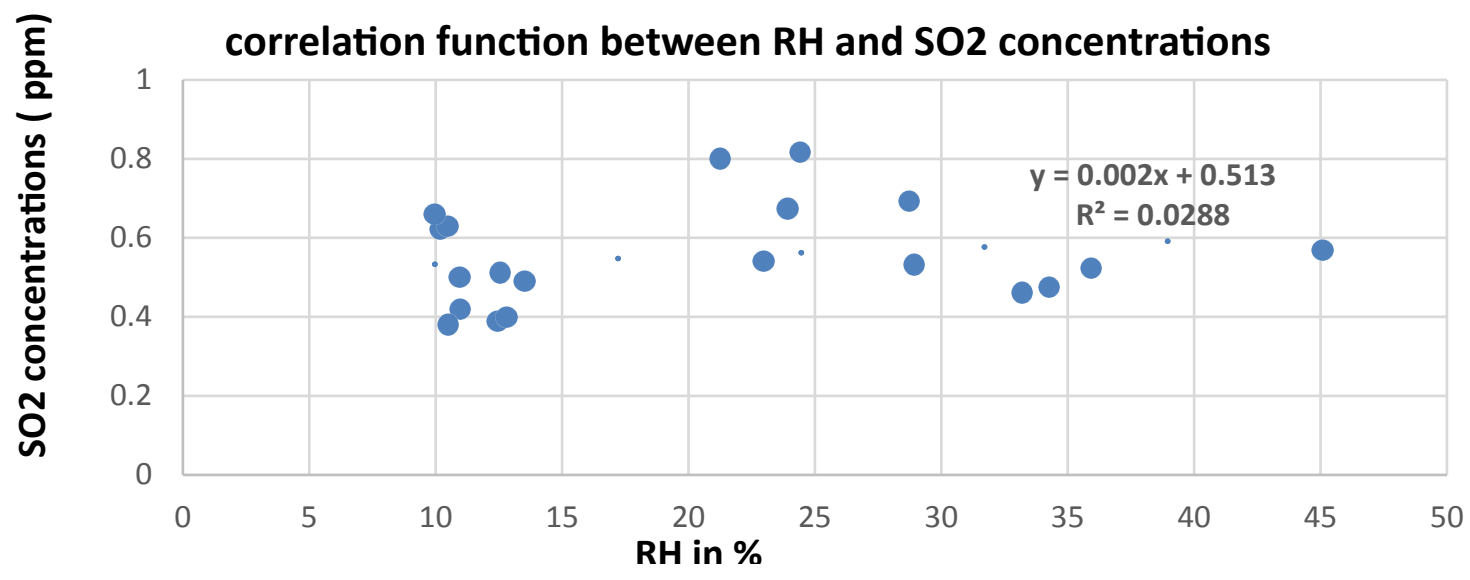

Figure 13: Correlation curve of $\mathrm{SO}_{2}$ concentrations with $\mathrm{RH}$.

Haghighhat et al. [33] predicted that the chamber formaldehyde concentration increases with increasing temperature. A further study [34] estimated that at least $1.3 \pm 0.4 \%$ increase in daily total (exhaust+evaporative) VOC emissions from motor vehicles per $1^{\circ} \mathrm{C}$ increase in maximum temperature. Also, Pusede et al. [35] found that tailpipe emissions from vehicles are only weakly temperature dependent, for example due to the increase in fuel consumption for air conditioning on hot days.

An Investigation carried out by Cetin et al. [48] showed that VOC concentrations varied seasonally and that concentrations were highest in summer, followed by autumn, probably due to increased evaporation of VOCs from fugitive sources as a result of higher temperatures. VOC concentrations generally increased with temperature and wind speed. Temperature accounted for $1-48 \%$ of the variability in VOC concentrations

\section{Carbon monoxide (CO)}

Statistical analysis and presentation of data show variation of $\mathrm{CO}$ levels monitored at the study area on 1-h and daily basis. CO levels experience slight increase during the second sampling period taken at $\mathrm{L}_{11}-\mathrm{L}_{20}$ simultaneous with change in meteorological factors. According to figures of Table 5, a weak positive correlation of CO levels with both relative humidity and temperatures can be suggested. Comparative studies reported that the level of $\mathrm{CO}$ decreases with increasing temperature, but $\mathrm{CO}$ increases with increasing relative humidity [14].

\section{Ozone concentrations}

In regard to monitored 1-h and daily ozone levels at study area, results exhibit little increase during the second sampling period after a change in climatic factors occurs. The analysis of data suggests that ozone concentrations increase, whilst $\mathrm{NO}_{2}$ concentrations decrease, indicating that vehicular emissions and transport process were large contributors to daily ozone production. In fact, a very weak negative correlation is found between ozone concentrations and the ambient $\mathrm{NO}_{2}$ levels at the study area. As presented in Figure 9, a correlation coefficient of $\mathrm{R}^{2}=0.0358$ is resulted, while a positive correlation could be seen between ozone production and ambient TVOC concentrations $\left(\mathrm{R}^{2}=0.2725\right)$ as shown in Figure 10.

Although many factors may influence ozone concentration, diurnal meteorological variations are the one that clearly explain diurnal variation of ozone concentrations. The most important meteorological parameters which influence ozone production are solar radiation (influencing the speed and amount of photochemical production of ozone), temperature (controlling, influencing the speed and amount of photochemical production of ozone), vertical temperature gradient (influencing the vertical mixing in the atmosphere surface winds (controlling the formation of the diurnal pattern of surface ozone concentrations in mountain valleys and coastal areas), aloft winds (responsible for the transport of ozone and its precursors), precipitation (decreasing the ozone concentration by means of wet deposition) and relative humidity [14].

As illustrated in Table 5, the correlation between relative humidity and ozone levels couldn't be clearly demonstrated. However a slight increase in ozone levels at locations $\mathrm{L}_{11}-\mathrm{L}_{20}$ is noticed and could be referred to the increase in ambient relative humidity during the sampling period. A very weak positive correlation between ozone concentrations and ambient $\mathrm{RH}$ was calculated with a correlation coefficient in the range of $\mathrm{R}^{2}=0.0642$. While practically no correlation $\left(\mathrm{R}^{2}=0.0002\right)$ with temperatures could be observed. This result can be probably explained because ground ozone production depends mainly on temperature and sun radiation. Bright sunshine was available during both monitoring periods, whilst the temperature experienced only a slight decrease of about $8 \%$ making no clear change in effect. A similar study [39] suggested a negative correlation between ozone and relative humidity, and a positive correlation between ozone and temperature. Similarly, Hosseinibalam et al. [49] suggested that temperature was positively correlated with most of the pollutant including ozone, except $\mathrm{NO}(r=-0.05)$ and $\mathrm{SO}_{2}(r=-0.07)$.

In addition, other investigation studies put the emphasis on the variations of $\mathrm{O}_{3}$ with the meteorological factors. They found that correspondent relations, more or less, existed between meteorological factors and $\mathrm{O}_{3}$ concentrations both in maximum and daily average. High $\mathrm{O}_{3}$ concentrations were related to low relative humidity, whilst a positive correlation between $\mathrm{O}_{3}$ and temperature was observed Nnenesi et al. $[39,50]$. Both confirmed a strong dependence of ground ozone on temperature and a correlation coefficient is found in the range of $\left(\mathrm{R}^{2}=0.8722\right)$. Whilst, Gorai et al. [7] reported that temperature profile in the area rarely had any effects on the ozone concentrations due to low spatial variations. Moreover, photochemical reactions of volatile 
Citation: Radaideh JA (2017) Effect of Meteorological Variables on Air Pollutants Variation in Arid Climates. J Environ Anal Toxicol 7: 478. doi: 10.4172/2161-0525.1000478

Page 11 of 12

organic compounds (VOCs) and nitrogen oxides $\left(\mathrm{NO}_{\mathrm{x}}\right)$ under high temperatures lead to ozone formation $[16,31]$.

In this study, VOC concentrations increase, whilst $\mathrm{NO}_{2}$ concentrations decrease. Often, $\mathrm{NO}_{\mathrm{x}}$ alone controls the ozone formation, but increases with increasing VOC $[31,43]$. This is probably the reason why no clear association of ozone formation with varying meteorological components could be established. Comparative studies revealed that ozone levels are at maximum during summer while minimum ozone levels occurs during winter months. Other study found that relative humidity $(\mathrm{RH})$ correlated negatively with most of the air pollutants and the strongest negative correlation was found with $\mathrm{O}_{3}$ with $r=-0.38$ [51]. Allison et al. found that changes in climate variables, including temperature and atmospheric moisture, cause increases to peak ozone concentrations on the order of a few ppb.

\section{$\mathrm{NO}_{2}$ concentrations}

The concentrations of $\mathrm{NO}_{2}$ are spatially very variable in the industrial areas, depending on time of the day, season, reactivity and meteorological factors and, as emissions of NOx are strongly trafficrelated, a rising trend regarding $\mathrm{NO}_{2}$ concentrations is to be expected in growing areas with high traffic density.

Results of this survey study show that monitored concentrations of $\mathrm{NO}_{2}$ varied between $0.38-0.66 \mathrm{ppm}$ at locations $\mathrm{L}_{1}-\mathrm{L}_{10}$ and $0.608-0.817$ ppm locations $\mathrm{L}_{11}-\mathrm{L}_{20}$, indicating a $53.4 \%$ decrease in mean values. A phenomenon to be attributed to the sudden increase in relative humidity and the change in ambient temperatures. Results of a related survey study showed that both $\mathrm{SO}_{2}$ and $\mathrm{NO}_{x}$ were negatively correlated in summer $\left(\mathrm{r}^{2}=0.25\right.$ for $\mathrm{SO}_{2}$ and $\mathrm{r}^{2}=0.15$ for $\left.\mathrm{NO}_{\mathrm{x}}\right)$ and moderately and positively correlated $\left(\mathrm{r}^{2}=0.32\right.$ for $\mathrm{SO}_{2}$ and $\mathrm{r}^{2}=0.51$ for $\left.\mathrm{NO}_{\mathrm{x}}\right)$ during postmonsoon season with temperature, which indicated that the influence of temperature on both $\mathrm{SO}_{2}$ and $\mathrm{NOx}$ is much more effective in summer than other seasons, due to higher temperature range. In addition it was found that no significant correlation was found between relative humidity and the gaseous pollutants $\mathrm{SO}_{2}$ and $\mathrm{NOx}$.

\section{$\mathrm{SO}_{2}$ concentrations}

The relationship between $\mathrm{SO}_{2}$ concentrations and the meteorological situation is not clear and is difficult to establish. Recorded concentrations of $\mathrm{SO}_{2}$ varied between $0.38-0.66 \mathrm{ppm}$ at locations $\mathrm{L}_{1}-\mathrm{L}_{10}$ and $0.461-$ 0.817 ppm locations $\mathrm{L}_{11}-\mathrm{L}_{20}$, resulting an $20.6 \%$ increase in average values. A clear dependency of this result with the relative humidity couldn't be established. However, the small increase in concentrations at locations $\mathrm{L}_{11}-\mathrm{L}_{20}$ compared to levels of $\mathrm{SO}_{2}$ monitored at $\mathrm{L}_{1}-\mathrm{L}_{10}$ could be referred to simultaneous increase in relative humidity. The overall correlation of $\mathrm{SO}_{2}$ concentrations with $\mathrm{RH}$ is according to Table 5 negative but weak with a correlation coefficient $\mathrm{R}^{2}=0.0288$. Observed concentrations correlate negatively weak to temperature with a correlation coefficient $\mathrm{R}^{2}=0.0358$.

Similar studies indicated that there is a moderate to weak level of correlation between the $\mathrm{SO}_{2}$ level and the meteorological factors [52]. As a general result, $\mathrm{SO}_{2}$ and total suspended particles (TSP) were slightly decreased with decreasing wind speed and temperature. However, $\mathrm{SO}_{2}$ was weakly increased with increasing relative humidity and atmospheric pressure [52]. A further study presented by Bridgman et al. [53], the relationship of $\mathrm{SO}_{2}$ concentrations to six major meteorological parameters has been investigated and found results suggested that $\mathrm{SO}_{2}$ concentrations strongly related to colder temperature, higher relative humidity and lower wind speed. However, a study Zhang et al. [12] has claimed that $\mathrm{SO}_{2}$ and $\mathrm{O}_{3}$ have no distinct relative humidity dependency.

\section{Conclusions}

This work is to our knowledge the most comprehensive analysis of air pollutants dataset related to weather variables from a country of the Middle Eastern region. Statistical models used for data analysis and explanations, establish how close relationships are between concentration estimates and values actually measured. The statistical models analysis confirmed that weather variables such as temperature and relative humidity have a significant impact on the most air pollutants. The study revealed a clear indication of the correlation between the concentrations of air pollutants and ambient temperatures and relative humidity.

i) The gaseous pollutant $\mathrm{SO}_{2}$ was negatively correlated with temperature and relative humidity $\left(\mathrm{R}^{2}=0.0358\right.$ for temperature and $\mathrm{R}^{2}=0.0288$ for relative humidity).

ii) The correlation of $\mathrm{NO}_{2}$ with relative humidity is negatively strong with $\mathrm{R}^{2}=0.7806$, but is positively correlated with ambient temperatures $\left(\mathrm{R}^{2}=0.648\right)$.

iii) In regard to ozone, a very weak positive correlation between ozone concentrations and ambient $\mathrm{RH}$ was calculated with a correlation coefficient in the range of $\mathrm{R}^{2}=0.0642$. While practically no correlation $\left(\mathrm{R}^{2}=0.0002\right)$ with temperatures could be observed.

iv) According to findings of this study, a weak positive correlation of $\mathrm{CO}$ levels with both relative humidity and temperatures can be suggested $\left(R^{2}=0.1747\right.$ for relative humidity and $R^{2}=0.0962$ for temperature, respectively).

v) Concentrations of collective term TVOC as monitored correlate strongly positive with increasing relative humidity $\left(\mathrm{R}^{2}=0.5692\right)$ and moderate negative with decreasing ambient temperatures $\left(\mathrm{R}^{2}=0.4289\right)$.

\section{References}

1. EPA (2008) National Ambient Air Quality Standards (NAAQS)

2. WHO (2000) Regional Office for Europe. Air quality guidelines for Europe. 2nd edn. Copenhagen, WHO Regional Publications, European Series pp: 91.

3. Kampa M, Castanas E (2008) Human health effects of air pollution. Environ Pollut 151: 362-367.

4. Karl B Schnelle, Brown CA (2001) Clean Air Act. Air Pollution Control Technology Handbook. ISBN 9781420036435.

5. Giri D, Murthy KV, Adhikary PR (2008) The Influence of Meteorological Conditions on PM10 Concentrations in Kathmandu Valley. Int. J. Environ. Res 2: 49-60.

6. D'amato G, Vitale C, De Martino A, Viegi G, Lanza M, et al. (2015) Effects on asthma and respiratory allergy of Climate change and air pollution. Multidisciplinary Respiratory Medicine 10: 39.

7. Gorai AK, Tuluri F, Tchounwou PB, Ambinakudige S (2015) Influence of loca meteorology and NO2 conditions on ground-level ozone concentrations in the eastern part of Texas, USA. Air Qual Atmos Health 8: 81-96.

8. Cheng CS, Campbell M, Li Q, Li G, Auld H, et al. (2007) Synoptic climatological approach to assess climatic impact on air quality in south-central Canada. Part II: future estimates. Water Air Soil Poll. 182: 117-130.

9. Elminir HK (2005) Dependence of urban air pollutants on meteorology. Sci Total Environ 350: 225-237.

10. Ordonez C, Mathis H, Furger M, Henne S, Hoglin C, et al. (2005) Changes of daily surface ozone maxima in Switzerland in all seasons from 1992 to 2002 and discussion of summer 2003. Atmos Chem Phys 5: 1187-1203.

11. Beaver S, Palazoglu A (2009) Influence of synoptic and mesoscale meteorology on ozone pollution potential for San Joaquin Valley of California. Atmos Environ 43: $1779-1788$.

12. Zhang H, Wang Y, Hu J, Ying Q, Hu XM (2015) Relationships between 
Citation: Radaideh JA (2017) Effect of Meteorological Variables on Air Pollutants Variation in Arid Climates. J Environ Anal Toxicol 7: 478. doi: $10.4172 / 2161-0525.1000478$

meteorological parameters and criteria air pollutants in three megacities in China. Environmental research 140: 242-254.

13. Csavina J, Field J, Félix O, Corral-Avitia AY, Sáez AE, et al. (2014) Effect of Wind Speed and Relative Humidity on Atmospheric Dust Concentrations in Semi-Arid Climates. Sci Total Environ 487: 82-90.

14. Ocak S, Turalioglu FS (2008) Effect of Meteorology on the Atmospheric Concentrations of Traffic- Related Pollutants in Erzurum, Turkey. J. Int. Environmental Application \& Science 3: 325-335.

15. Jacob DJ, Winner DA (2009) Effect of climate change on air quality. Atmospheric Environment 43: 51-63.

16. Seinfeld JH, Pandis SN (1998) Atmospheric Chemistry and Physics: From Air Pollution to Climate Change. 2nd edn. Wiley, USA. ISBN: 978-0-471-72018-8.

17. Gillespie Alexander (2006) Climate Change, Ozone Depletion and Air Pollution: Legal Commentaries Within the Context of Science And Policy. ISBN: 9004145206, 9789004145207.

18. Hien PD, Bac VT, Tham HC, Nhan DD, Vinh LD (2002). Influence of meteorological conditions on PM2.5 and PM 2.5 concentrations during the monsoon season in Hanoi, Vietnam. Atmospheric Environment 36: 3473-3484.

19. Baertsch-Ritter N, Keller J, Dommen J, Prevot ASH (2004) Effects of various meteorological conditions and spatial emission resolutions on the ozone concentration and ROG/NOx limitation in the Milan area (I). Atmospheric Chemistry and Physics 4: 423-438.

20. Wise EK, Comrie AC (2005) meteorologically adjusted urban air quality trends in the Southwestern United States. Atmospheric Environment 39: 2969-2980.

21. Cox WM, Chu SH (1996) Assessment of inter-annual ozone variation in urban areas from a climatological respective. Atmospheric Environment 14: 2615-2625.

22. Diffenbaugh NS, Pal JS, Giorgi F, Gao X (2007) Heat stress intensification in the Mediterranean climate change hotspot. Geophysical Research Letters 34: L11706.1- L11706.6.

23. Novlan DJ, Hardiman M (2007) A synoptic climatology of blowing dust events in El Paso, Texas from 1932-2005. Conference on Applied Climatology, American Meteorological Society 12: 13.

24. Quintero E, Rivera-Mariani F (2010) Analysis of environmental factors and their effects on fungal spores in the atmosphere of a tropical urban area (San Juan, Puerto Rico). Aerobiologia 26: 113-124.

25. Zauli Sajani S, Bonasoni P, Cristofanelli P, Marinoni A, Lauriola P (2012) Only Coarse Particles from the Sahara? Epidemiology 23: 642-643.

26. Camalier L, Cox W, Dolwick P (2007) The effects of meteorology on ozone in urban areas and their use in assessing ozone trends. Atmos Environ 41: 7127-7137.

27. Schlink U, Herbarth O, Richter M, Dorling S, Nunnari G, et al. (2006) Statistical models to assess the health effects and to forecast ground-level ozone. Environ Model Softw 21: 547-558.

28. Marignani M, Bruschi D, Astiaso Garcia D, Frondoni R, Carli E, et al. (2017) Identification and prioritization of areas with high environmental risk in Mediterranean coastal areas: A flexible approach. Sci Total Environ 590-591: 566-578.

29. WHO (2006) Regional Office for Europe. Air quality guidelines global update 2005: Particulate matter, ozone, nitrogen dioxide and sulfur dioxide. Copenhagen.

30. Murrells T, Derwent RG (2007) Climate Change Consequences of VOC Emission Controls. Report to The Department for Environment, Food and Rural Affairs, Welsh Assembly Government, the Scottish Executive and the Department of the Environment for Northern Ireland. ED48749102. AEAT/ ENV/R/24753.

31. Im U, Incecik S, Guler M, Tek A, Topcu S, et al. (2013) Analysis of surface ozone and nitrogen oxides at urban, semi-rural and rural sites in Istanbul, Turkey. Sci Total Environ 443: 920-931.

32. EU (2007) Directive 2004/42/CE of the European Parliament and the Council. EUR-Lex. European Union Publications Office.
33. Haghighat F, Bellis DL (1998) Material emission rates: literature review and the impact of indoor air temperature and relative humidity. Building and Environment 33: 261-277.

34. Rubin JI, Kean AJ, Harley RA, Millet DB, Goldstein AH (2006) Temperature dependence of volatile organic compound evaporative emissions from motor vehicles. J Geophys Res pp: 111

35. Pusede SE, Cohen RC (2012) On the observed response of ozone to NOx and VOC reactivity reductions in San Joaquin Valley California 1995-present. Atmospheric Chemistry and Physics 12: 8323-8339.

36. Wolkoff $P$ (1998) Impact of air velocity, temperature, humidity and air on longterm VOC emissions from building products. Atmospheric Environment 32 : 2659-2668.

37. Bremer J, White E, Schneider D (1993) Measurement and characterization of emissions from PVC materials for indoor use. Proceedings of the Sixth International Conference on Indoor Air Quality and Climate 2: 419-424.

38. Cox SS, Little JC, Hodgson AT (2005) Effect of glass transition temperature on volatile emissions from polymer materials. Proceedings of Indoor Air II (1):1845-1849

39. Nnenesi Dr, Kgabi A, Ramotsamai Sehloho M (2012) Seasonal Variations of Tropospheric Ozone Concentrations. Global Journal for Science Frontier Research 12: 5-B.

40. Rodrigue JP (2017) The Geography of Transport systems. 4th edn. Oxford University Press. ISBN 978-1138669574.

41. Kho FWL, Law PL, Ibrahim SH, Sentian J (2007) Carbon monoxide levels along roadway. Int. J. Environ. Sci. Tech 4: 27-34.

42. Zhou Y, Cheng S, Chen D, Lang J, Wang G, et al. (2015) Temporal and Spatial Characteristics of Ambient Air Quality in Beijing, China. Aerosol and Air Quality Research 15: 1868-1880

43. Sillman S, Logan JA, Wofry SC (1990) A regional-scale model for ozone in the United States with a subgrid representation of urban and power plant plumes. J Geophys Res. 95: 5731-5748.

44. Rodrigo JS, Raúl GE, Morales S, Manuel A, Leiva G (2012) Ozone weekend effect in Santiago, Chile. Environmental Pollution 162: 72-79.

45. Menz FC, Seip HM (2007) Acid rain in Europe and the United States: An update. Environ. Sci. Policy 7: 253-265.

46. Gupta A, Ranjit K, Maharaj K, Srivastava SS (2003) Measurement of NO2, H $\mathrm{NO} 3, \mathrm{NH} 3$ and $\mathrm{SO} 2$ and related particulate matter at a rural site in Rampur, India. Atmospheric Environment 37: 4837-4846.

47. Salmond JA, Williams DE, Laing G, Kingham S, Dirks K, et al. (2013) The influence of vegetation on the horizontal and vertical distribution of pollutants in a street canyon. Science of the Total Environment 443: 287-298.

48. Cetin E, Odabasi M, Seyfioglu R (2003) Ambient volatile organic compound (VOC) concentrations around a petrochemical complex and a petroleum refinery. The Science of the Total Environment 312: 103-112.

49. Hosseinibalam F, Azadeh Hejazi A (2012) Influence of Meteorological Parameters on Air Pollution in Isfahan. 3rd International Conference on Biology. Environment and Chemistry IPCBEE pp: 10

50. Punithavathy IK, Vijayalakshmi S, Jeyakumar SJ (2015) Assessment of Ground-Level Ozone and its Variability with Meteorological Parameters at Karaikal, India. Universal Journal of Environmental Research and Technology 5: 233-240.

51. Habeebullah TM, Munir S, Ropkins K, Morsy E, Mohammed A, et al. (2015) A comparison of air quality in arid and temperate climatic conditions - a case study of Leeds and Makkah. Int. J. Environ. Ecol. Eng 1: 661

52. Akpinar EK, Akpinar S, Öztop HK (2009) Statistical analysis of meteorological factors and air pollution at winter months in Elazig, Turkey. Journal of Urban and Environmental Engineering 3: 7-16.

53. Bridgman HA, Davies TD, Jickells T, Hunova I, Tovey K, et al. (2002) Air pollution in the Krusne Hory region, Czech Republic during the 1990s. Atmospheric Environ 33: 75-89. 